Corresponding author: sofia.douzgou.houge @helse-bergen.no

(C) 2021 Berland et al. This article is distributed under the terms of the Creative Commons

Attribution-NonCommercial License, which permits reuse and redistribution, except for commercial purposes, provided that the original author and source are credited.

Ontology terms: facial midline hemangioma; large placenta; macrocephaly at birth; macrocephaly due to hydrocephalus; polyhydramnios; question mark ear

Published by Cold Spring Harbor Laboratory Press

doi:10.1101/mcs.a006121

\section{The blended phenotype of a germline RIT1 and a mosaic PIK3CA variant}

\author{
Siren Berland, ${ }^{1}$ Jørgen Jareld, ${ }^{2}$ Nicholas Hickson, ${ }^{3}$ Helene Schlecht, ${ }^{3}$ \\ Gunnar Houge, ${ }^{1,4}$ and Sofia Douzgou ${ }^{1,3,4}$ \\ ${ }^{1}$ Department of Medical Genetics, Haukeland University Hospital, N-5021, Bergen, Norway; ${ }^{2}$ Department of \\ Paediatrics, Ålesund Hospital, Møre and Romsdal Health Trust, 6026, Ålesund, Norway; ${ }^{3}$ Manchester Centre \\ for Genomic Medicine, St Mary's Hospital, Manchester University Hospitals NHS Foundation Trust, \\ Manchester Academic Health Sciences Centre, Oxford Road, M13 9WL, United Kingdom; ${ }^{4}$ Division of \\ Evolution and Genomic Sciences, School of Biological Sciences, University of Manchester, Oxford Road, \\ M13 9PL, United Kingdom
}

Abstract We report a patient with a germline RIT1 and a mosaic PIK3CA variant. The diagnosis of the RASopathy was confirmed by targeted sequencing following the identification of transient cardiomyopathy in a patient with PIK3CA-related overgrowth spectrum (PROS). Our observation confirms that the PIK3CA gain-of-function (GoF) variant effects dominate those of the RASopathy, and the resulting blended phenotype mostly resembles megalencephaly-capillary malformation syndrome (MCAP PROS). There appears to be interaction between RIT1 and PI3K-AKT because the latter pathway is needed for the growth-promoting activity of the first, at least in adenocarcinomas, but the details of this interaction are not known. If so, the PIK3CA somatic variant may not be just a chance event. It could also be of etiological relevance that Rit activation mediates resistance to cellular stress-that is, promotes cell survival. This anti-apoptotic effect could also make it more likely that a cell that spontaneously acquires a PIK3CA GoF variant will survive and proliferate. We aim to encourage clinicians to investigate atypical findings in individuals with PROS. If further similar cases are reported, this would suggest that the establishment of PROS mosaicism is facilitated by the background of a RASopathy.

\section{CASE PRESENTATION}

A female patient, born following a pregnancy complicated by large fetal size evidenced at 30 wk of gestation by 3D ultrasound (US), was delivered via cesarean section because of large size at $35.5 \mathrm{wk}$. At delivery, there was excess amniotic fluid $(\sim 1.2 \mathrm{~L})$, and the placenta weighed $1 \mathrm{~kg}$. Birth growth parameters were birth weight $(B W) 5178 \mathrm{~g}(Z$-score $=3)$, length $54 \mathrm{~cm}(Z$-score $=2.5)$, and head circumference $(\mathrm{HC}) 43 \mathrm{~cm}(Z$-score $=3)$. Her Apgar scores were $6,8,8$. She was born cyanotic and required respiratory support (ventilator) during the first day of life. A cardiac Doppler US evidenced pulmonary hypertension and patent ductus arteriosus (PDA) with bidirectional shunting. She also had mild hypoglycemia initially (the lowest blood glucose level was $1.9 \mathrm{mmol} / \mathrm{L}$ ). Dysmorphic features were noticed including a midline philtrum nevus flammeus and sacral hemangioma, large mouth, question mark right ear, mild pectus excavatum (Fig. 1), and diastasis recti.

She was discharged after $10 \mathrm{~d}$ but soon readmitted because of signs of heart failure (hypotonia, reduced appetite, and sweating during breastfeeding). Repeat cardiac Doppler US evidenced large right ventricle and tricuspid and pulmonary valve insufficiency. She was 


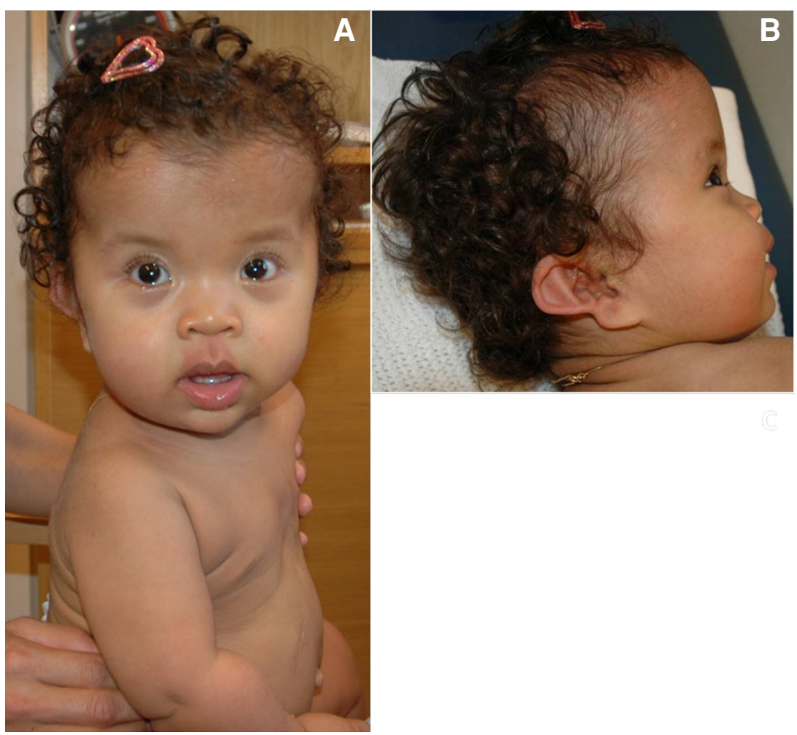

Figure 1. (A) Broad forehead, broad nose with short columella, low nasal bridge, philtral hemangioma, and slight pectus excavatum. (B) Question mark-shaped right ear.

placed on treatment with diuretics (furosemide $5 \mathrm{mg} \times 3$ ) with good effect (brain natriuretic peptide levels fell from 8126 to 258 in 2 d). Abdominal US revealed hepatomegaly, and a cranial US showed asymmetric, enlarged ventricles (Right > Left). A skeletal survey showed normal results apart from gracile ribs and a relatively smaller, bell-shaped thorax. Automated auditory brain stem response (AABR) showed hearing within normal limits.

Brain magnetic resonance imaging (MRI) at age 6 mo showed hydrocephalus with larger third and fourth ventricles, likely bilateral parietal polymicrogyria, Chiari malformation, and no vascular malformations (Fig. 2). The girl was shunted (third ventricle ventriculostomy, ventricular-peritoneal [VP] shunt). Liver appearances were normalized on repeat abdominal US (no enlargement). Cardiac failure slowly resolved with improvement of US findings (spontaneous closure of the PDA, reduced pulmonary hypertension, and good contractility) and a normal electrocardiogram. Cardiac computed tomography imaging identified a right-lying aortic arch with an aberrant left subclavian artery forming a vascular ring with the aortic arch (right side), the left common carotid artery (ventral), and the left subclavian artery (dorsal).

The VP shunt failed at $5 \mathrm{yr}$ of age but was no longer required and was removed at the age of $14 \mathrm{yr}$. At $2 \mathrm{yr}$ she had absence episodes; a standard electroencephalogram (EEG) was normal. Three years later she developed focal epilepsy with several episodes with partial loss of consciousness lasting $60 \mathrm{sec}$ on average and vomiting afterward. A repeated EEG revealed interictal epileptic activity (occipital/temporal regions on the left side). She was initially treated with oxcarbazepine with partial control and then with lamotrigine, which successfully controlled the seizures. A repeated EEG at $8 \mathrm{yr}$ did not evidence epileptic activity. Anti-epileptic medication was paused at the age of $9 \mathrm{yr}$ without any recurrence since.

Growth evolution was as follows: $\mathrm{HC}$ measurements were $3 \mathrm{yr}, 63 \mathrm{~cm} ; 7 \mathrm{yr}, 64 \mathrm{~cm} ; 8 \mathrm{yr}$, $64.5 \mathrm{~cm} ; 12 \mathrm{yr}, 66.5 \mathrm{~cm}$-all $8 \mathrm{~cm}$ above $Z$-score $=3$. Her height $(\mathrm{Ht})$ progressed from significantly below the normal at age $25.5 \mathrm{yr}(Z$-score $=-3) \mathrm{cm}$ to $Z$-score $=-1.9$ at age $8 \mathrm{yr}$ and Zscore $=0$ at age $10 \mathrm{yr}(\mathrm{Ht}$ at $5 \mathrm{yr}, 99 \mathrm{~cm} ; 8 \mathrm{yr}, 117 \mathrm{~cm} ; 10 \mathrm{yr}, 141 \mathrm{~cm} ; 11 \mathrm{yr}, 149.5 \mathrm{~cm} ; 12 \mathrm{yr}, 157$ $\mathrm{cm})$, but she had menarche at $8 \mathrm{yr}$ and also growth hormone treatment for $1 \mathrm{yr}$ (10-11 yr of age). She has regular but heavy menstruation often accompanied by migraines managed 
C OLD SPRING HARBOR Molecular Case Studies
MCAP PROS and germline RASopathy

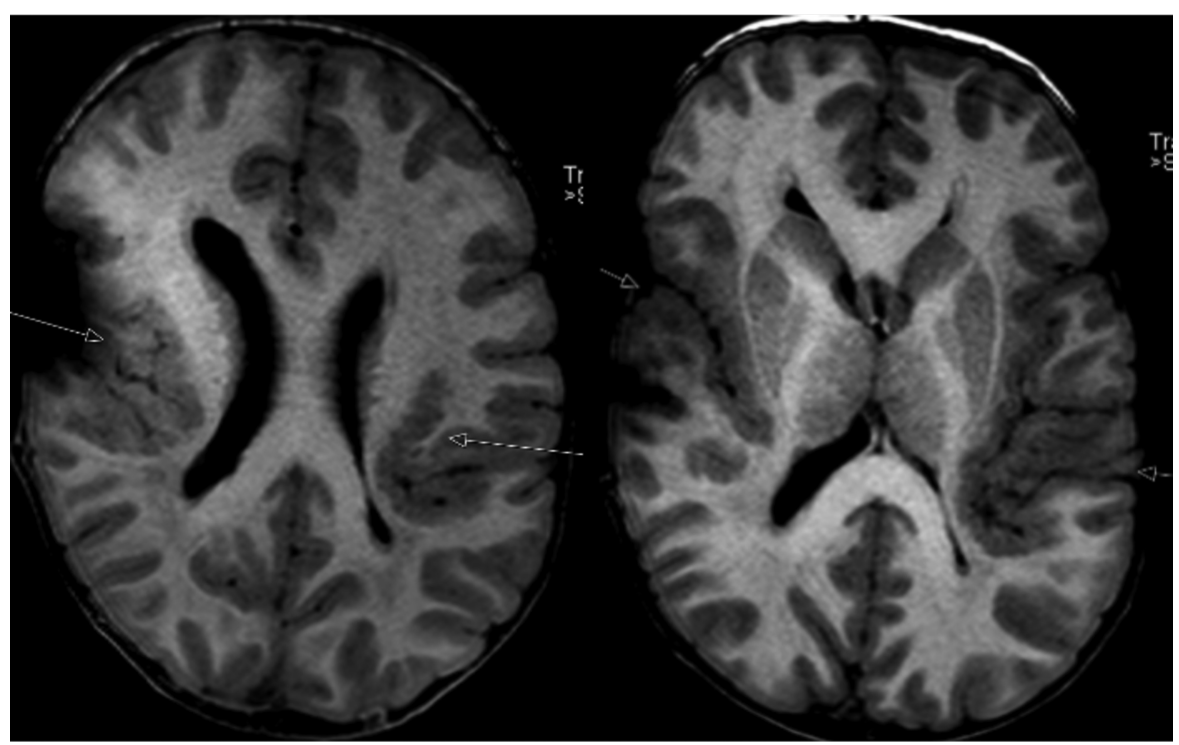

Figure 2. Axial brain magnetic resonance imaging (MRI), T1 inversion recovery (IR) sequences at 4 yr of age that show probable polymicrogyria in the region of both Sylvian fissures (arrows).

with ibuprofen $(4000 \mathrm{mg} \times 3)$. She also takes omeprazole $(20 \mathrm{mg} \times 1)$ for gastroesophageal reflux.

She manifested moderate developmental delay. She sat without support at age $1.5 \mathrm{yr}$ and walked without support at $6 \mathrm{yr}$. She spoke first words at $2 \mathrm{yr} 4 \mathrm{mo}$ and in full sentences at 6 yr. Wechsler Intelligence Scale for Children (WISC) test assessment evidenced moderate intellectual disability (International Classification of Diseases, ICD10 F71) with reduced cognitive abilities both verbal and nonverbal. She demonstrated rigid behavior with problems in social communication and play. An Autism Diagnostic Observation Schedule 2 (ADOS-2) test showed results within normal limits. Family history is noncontributory; she has two older, healthy, maternal half-siblings.

Plasma amino acids, urine purines and pyrimidines, lysosomal enzymes activity test in both blood and fibroblast cultures, and transferrin isoelectric focusing (TfIEF) screening for congenital disorders of glycosylation showed normal results. Diagnostic genetic testing started around her birth, $15 \mathrm{yr}$ ago, and was completed gradually, several years later, as relevant tests were becoming available in a clinical diagnostic setting of the public health service of Norway and extended Europe. A standard karyotype was normal $(46, X X)$, and so was a genomic copy-number array (Affymetrix 250K SNP-array). Neonatally, both BeckwithWiedemann syndrome (BWS; MIM \#130650) and Costello syndrome (MIM \#218040) were suspected; HRAS (MIM *190020) Sanger sequencing and BWS methylation analysis showed normal results. Genetic testing did not include CDKN1C (MIM *600856) Sanger sequencing as the individual was diagnosed clinically with megalencephaly-capillary malformation syndrome (MCAP; PIK3CA-related overgrowth spectrum [PROS], MIM \#602501). This diagnosis was confirmed molecularly at a later stage as the family consented to skin biopsy only during general anesthesia. Additionally, on the basis of the history of a neonatal presentation reminiscent of a RASopathy including transient cardiomyopathy (Gripp et al. 2020), which is an atypical symptom for MCAP PROS, Sanger sequencing of a targeted Ras-MAPK gene panel, which became available even later, was also performed (see Technical Analysis). After this, there was no clinical indication for further genetic testing through more extended next-generation sequencing (NGS) panels. 
Table 1. Genomic findings

\begin{tabular}{|c|c|c|c|c|c|c|}
\hline Gene & Genomic location & HGVS cDNA & HGVS protein & Zygosity & $\begin{array}{l}\text { Parent } \\
\text { of origin }\end{array}$ & $\begin{array}{l}\text { ACMG variant } \\
\text { interpretation }^{a}\end{array}$ \\
\hline RIT1 & $\begin{array}{l}\text { Chr 1(GRCh37): } \\
\text { g.155874166C >A }\end{array}$ & $\begin{array}{c}\text { NM_006912.5: } \\
\text { c.365G > T }\end{array}$ & p.(Arg122Leu) & Heterozygous & De novo & $\begin{array}{c}\text { Class 4-likely } \\
\text { pathogenic }\end{array}$ \\
\hline PIK3CA & $\begin{array}{l}\text { Chr 3(GRCh37): } \\
\text { g.178921552A >C }\end{array}$ & $\begin{array}{l}\text { NM_006218.2: } \\
\text { c. } 1034 A>C\end{array}$ & p.(Asn345Thr) & $\begin{array}{l}\text { Fibroblasts, direct DNA extraction } \\
\text { from affected skin tissue, } 54 \% \\
\text { variant allele frequency (VAF); also } \\
\text { present in blood and buccal swab } \\
\text { (mosaic, exact VAF unknown) }\end{array}$ & $\begin{array}{l}\text { Not } \\
\text { tested }\end{array}$ & $\begin{array}{l}\text { Class 5- } \\
\text { pathogenic }\end{array}$ \\
\hline
\end{tabular}

(HGVS) Human Genome Variation Society, (ACMG) American College of Medical Genetics.

${ }^{\text {a }}$ From Richards et al. (2015).

\section{TECHNICAL ANALYSIS}

We performed a variant screen on DNA extracted from the patient's cultured skin fibroblasts sample to detect pathogenic variants in a number of genes known to be associated with segmental overgrowth syndromes. DNA sequence analysis identified a somatic PIK3CA variant as described in Table 1. No other variants were detected between this patient's sample and the reference sequences (except recognized polymorphisms). Long-range polymerase chain reaction (PCR) and next-generation sequencing on Illumina MiSeq were used to analyze the entire coding region and flanking sequences to \pm 50 bp of PIK3CA (LRG_310t1) and PTEN (LRG_311t1) and targeted exons for PIK3R2 (NM_005027.2), AKT1 (LRG_721t1), AKT3 (NM_005465.4), CCND2 (NM_001759.3), and mTOR (LRG_734t1). A minimum of 100 × coverage and an exonic mean of $1000 \times$ read depth. Regions with $<100 \times$ coverage were retested via Sanger sequencing using BigDye v3.1. Variant calling was via an in-house bioinformatics pipeline, validated to detect mutations down to at least $5 \%$ admixture, and named according to Human Genome Variation Society (HGVS) guidelines (http://www .hgvs.org) using reference sequences above. The PIK3CA variant was confirmed by Sanger sequencing (using BigDye v3.1), sensitive down to a $15 \%$ variant level (Mirzaa et al. 2016). DNA from the tested cultured skin fibroblast sample was used as a mutation positive control. Sanger sequencing confirmed the presence of the PIK3CA variant in a mosaic state in the patient's blood sample and was apparently heterozygous in a buccal swab sample. Sanger sequencing of a targeted Ras-MAPK gene panel (PTPN11, SOS1, RAF1, RIT1, BRAF, SHOC2, KRAS, HRAS, MAP2K1, and MAP2K2) detected a de novo missense variant in RIT1 (Table 1).

\section{VARIANT INTERPRETATION}

The PIK3CA variant is previously reported to be associated with PROS and is consistent with the clinical presentation of MCAP PROS (Mirzaa et al. 2016). The RIT1 variant has been found in another in-house sample referred for targeted Noonan syndrome (NS) testing with the indication of polyhydramnios (BW $=2220 \mathrm{~g}$, week $32+0$ [Z-score $=3.5]$; chylothorax and valvular pulmonary stenosis; small ventricular septal defect [VSD]; right-sided cryptorchidism; and requiring a percutaneous endoscopic gastrostomy [PEG] tube). No functional assays were performed, but the variant has previously been tested in a soft agar NIH3T3 cell transformation assay and found to induce cellular transformation of the same degree as the recurrent oncogenic Met901lle RIT1 variant (Berger et al. 2014). Both variants are found in a 
subset (2\%) of lung adenocarcinomas, and cellular transformation is dependent on both the MEK and the PI3K signaling pathways.

\section{SUMMARY}

Our patient is the second reported observation of a germline RASopathy and a somatic PIK3CA variant causing MCAP PROS. Döcker et al. (2015) described an individual with a germline PTPN11 and a somatic PIK3CA variant. Activating variants in PIK3CA cause the phenotypic spectrum known as the PIK3CA-related overgrowth spectrum (PROS) (Keppler-Noreuil et al. 2015). Deep sequencing technologies have facilitated the identification and clinical testing for PROS-related GoF variants that are often found as ultra-low-frequency mosaic variants in tissue other than blood (Mirzaa et al. 2016). The mosaicism causes a phenotypic spectrum that is variable in nature, extent, progression, and severity of the clinical presentation. One of the presentations within PROS is MCAP syndrome defined by the major findings of megalencephaly, associated with neurologic findings of hypotonia, seizures, and mild to severe intellectual disability as well as cutaneous capillary malformations with focal or generalized somatic overgrowth. Affected individuals may also present poly/ syndactyly, cortical malformations (most distinctively, polymicrogyria [PMG]), and variable connective tissue dysplasia (Mirzaa et al. 2013). RIT1 belongs to the RAS (HRAS; 190020) subfamily of small GTPases (Hynds et al. 2003), and Aoki et al. (2013) showed that GoF RIT1 variants cause NS. The RIT1-related NS is characterized by the high frequency of hypertrophic cardiomyopathy and lymphatic malformations that can also be later-onset. Other heart defects include cardiac septal defects and valvular insufficiencies. On the other hand, ectodermal abnormalities such as curly hair and hyperkeratosis are relatively uncommon in RIT1-related NS (Kouz et al. 2016).

The RIT1 Arg122Leu substitution found in our patient must also be growth-promoting, as evidenced by the birth macrosomia (5178 $\mathrm{g}$ in week 35.5) and large placenta (1 kg) and a positive transformation assay of NIH3T3 cells in soft agar (Berger et al. 2014). Oncogenic RIT1 variants, like this one, have recently been shown to weaken mitotic assembly checkpoints and accelerate mitosis (Vichas et al. 2021). It is unknown if the PIK3CA Asn345Thr substitution also contributes to this, but neither fetal macrosomia nor placentomegaly are known PROS features. Of note, placentomegaly is not a recognized feature of a RASopathy either, unlike fetal macrosomia. However, because growth-promoting RIT1 signaling seems independent of KRAS but not PTPN11 and SOS1 (Vichas et al. 2021), an effect on placental growth that is not seen in most other RASopathies is conceivable. The reason for this is that other RASopathy genes signal through a cascade involving KRAS, and RIT1 signaling appears KRAS-independent. It has also been speculated that RIT1 stimulates receptor tyrosine kinases like GRB2 and IGF1R directly (Vichas et al. 2021). Taken together, both the RIT1 and the PIK3CA variants are undoubtedly growth-promoting - the first mainly during fetal development, the second during somatic development.

The wider availability of NGS (exome and genome) showed that $~ 5 \%$ of individuals tested had more than one, independently segregating, molecular diagnoses (Posey et al. 2017). So it is not uncommon to have two genetic conditions and likely more common than we think to have germline and mosaic variants. Individuals with multiple molecular diagnoses can present with clinical features that represent a blending of two or more phenotypes that may also suggest an apparent atypical or broader presentation of one of the conditions (Boycott and Innes 2017; Posey et al. 2017). The pre- and neonatal presentation of the individual presented here showcases the significant overlap between developmental disorders caused by GoF variants of the RAS-MAPK and the PI3K-AKT pathways. The girl was diagnosed with MCAP on the basis of the characteristic combination of megalencephaly, hydrocephalus, 
Table 2. Clinical findings

- Published by Cold Spring Harbor Laboratory Press
\[ \text { MCAP PROS and germline RASopathy } \]
$\begin{array}{ccc} & \\ \text { MCAP PROS }^{\text {a }} & \text { RIT1 Noonan } & \text { Proband, } 15 \text { yr old } \\ + & + & + \\ + & + & -\end{array}$

\section{Pre- and neonatal}

Polyhydramnios

Hydrops

Large placenta

Neonatal hypoglycemia

\section{Growth}

Increased birth weight

Failure to thrive

Feeding difficulties

Short stature

Somatic overgrowth, asymmetric

Hemihyperplasia

Head and neck

Megalencephaly

Macrocephaly, including relative

Craniofacial dysmorphisms

Broad forehead

Smooth philtrum

Fleshy earlobes

Epicanthus

Hypertelorism

Downslanting palpebral fissures

Flattened nasal bridge

Ptosis

Webbed/short neck

\section{Cardiovascular}

Ventricular septal defect

Pulmonary valve stenosis

Hypertrophic cardiomyopathy

Atrial septal defect

Valvular insufficiency

Lymphatic anomalies

Musculoskeletal

Truncal hypotonia

Joint laxity

Thorax deformity

One- to four-limb poly/syndactyly

Hernias

Skin, hair, and nails

Curly hair

Thick, loose, doughy skin

Cutaneous vascular malformations

Cutis marmorata

Keratosis pilaris
MCAP PROS

Proband, $15 \mathrm{yr}$ old
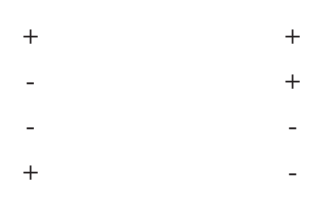

$+$

$-$

$+$

-

$+$

$+$

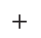

$+$

$+$

$-$

$-$

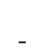

-

$-$

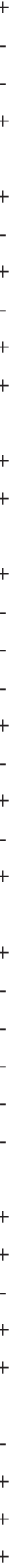

(n)

Transient

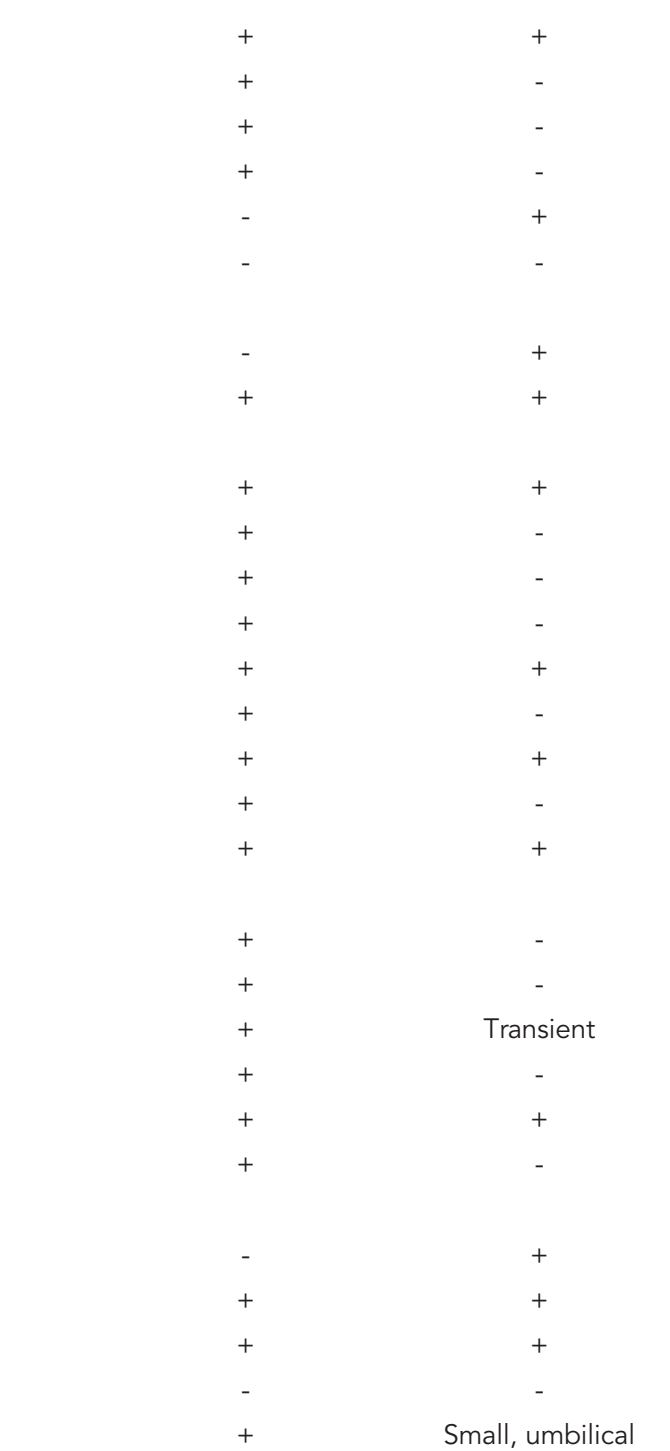

Small, umbilical

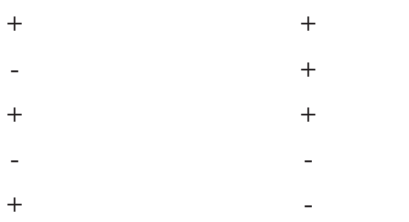

RIT1 Noonan 西

(Continued on next page.) 


\begin{tabular}{lccc}
\hline Table 2. (Continued) & & & \\
\hline & MCAP PROS $^{\mathrm{a}}$ & RIT1 Noonan $^{\mathrm{b}}$ & Proband, 15 yr old $^{\text {PCA }}$ \\
\hline Neurologic & & & \\
Central nervous system & + & + & + \\
$\quad$ Developmental delay & + & + & + \\
Intellectual/learning disability & + & + & + \\
Hypotonia & + & + & + \\
Seizures and or epilepsy & + & - & + \\
Brain asymmetry & + & - & + \\
Ventriculomegaly & + & + & + \\
Hydrocephalus & + & - & + \\
Cerebellar tonsil herniation & + & - & - \\
Polymicrogyria & + & + & + \\
Rare neoplasia & + & & + \\
\hline
\end{tabular}

(MCAP) Megalencephaly-capillary malformation syndrome, (PROS) PIK3CA-related overgrowth spectrum.

The list of clinical features are based on the OMIM clinical synopsis (\#602501; MEGALENCEPHALY-CAPILLARY MALFORMATION-POLYMICROGYRIA SYNDROME; MCAP).

${ }^{\text {b}}$ The list of clinical features are based on the OMIM clinical synopsis (\#615355; NOONAN SYNDROME 8; NS8) and adapted from Kouz et al. (2016).

polymicrogyria, and midline hemangiomas, but it was the indication of a congenital heart defect and transient cardiomyopathy that prompted further, targeted testing for NS. On the other hand, our observation evidences that the PIK3CA GoF variant effects dominate those of the RIT1 one phenotypically, and the resulting blended phenotype mostly resembles MCAP PROS at the age of $15 \mathrm{yr}$ (Table 2). Moreover, taking into consideration the phenotypes produced by each gene, a more noticeable hypertelorism (Fig. 1), and a significant macro- and megalencephaly ( $8 \mathrm{~cm}$ beyond $Z$-score $=3$ at $15 \mathrm{yr}$ ) than the ones usually observed in individuals with each one of the molecular diagnoses suggests that the blended phenotype may be more severe than one gene change alone. A question mark-shaped ear has been reported once before in a patient with MCAP (Robertson et al. 2000), but this feature cannot be firmly assigned to MCAP PROS, especially given this individual already has two diagnoses and it could be ascribed to either one as a rare finding or to something different altogether. Our observation should encourage clinicians to further investigate findings that are atypical or more severe than anticipated in individuals with PROS.

Döcker et al. (2015) built a "second hit" hypothesis and suggested a synergy of the RASMAPK and the PI3K-AKT in causing a developmental disorder based on molecular "crosstalk" between the two growth-promoting pathways. There appears to be interaction between RIT1 and PI3K-AKT because the latter pathway is needed for the growth-promoting activity of the first, at least in adenocarcinomas (Berger et al. 2014), but the details of this interaction are not known. Because the PIK3K pathway is needed for the growth-promoting effect of Arg122Leu in cancer cells (Berger et al. 2014), the acquisition of a somatic mutation in the same pathway could be facilitated and have a synergistic effect on growth. If so, the second somatic mutation is not just a chance event. It could also be of etiological relevance that Rit activation mediates resistance to cellular stress-that is, promotes cell survival (Shi et al. 2011). This anti-apoptotic effect could also make it more likely that a cell that spontaneously acquires a PIK3CA GoF variant will survive and proliferate. If further similar cases are reported, this would suggest that the establishment of PROS mosaicism is facilitated by the background of a RASopathy. 


\section{ADDITIONAL INFORMATION}

\section{Database Deposition and Access}

The RIT1 variant was submitted to ClinVar (https://www.ncbi.nlm.nih.gov/clinvar/) and can be found under accession numbers SCV001950189 for SUB10453075 and SCV001950190 for SUB10453086.

\section{Ethics Statement}

Because the finding was a consequence of routine clinical evaluation and diagnostics, and further research did not require patient investigations that would not otherwise have been done, ethical review board evaluation is not required according to Norwegian rules, and IRB requests will in such cases be rejected (Houge 2015). Written and oral consent from the patient's parents was obtained.

\section{Author Contributions}

Competing Interest Statement

The authors have declared no competing interest.

\section{Referees}

Wei-Liang Chen

Anonymous

Received June 28, 2021; accepted in revised form August 31, 2021.
S.B. and J.J. examined, investigated, and cared for the patient and the family, provided clinical information, and obtained the family's informed consent. N.H. and H.S. performed the segmental overgrowth technical analysis in multiple tissues. G.H. supervised all technical analysis, variant interpretation, and genomic findings reporting and critically revised the manuscript. S.D. conceived, designed, wrote, and submitted the manuscript.

\section{Acknowledgments}

We thank the family for consenting to share their story. We thank Dr. Kjell Arne (Department of Paediatric Radiology, St Olav Hospital, Trondheim, Norway) for the interpretation of the brain magnetic resonance images (Fig. 2). We thank Bjørn Ivar Haukanes, Department of Medical Genetics, Haukeland University Hospital, for his help with variant database deposition and access.

\section{REFERENCES}

Aoki Y, Niihori T, Banjo T, Okamoto N, Mizuno S, Kurosawa K, Ogata T, Takada F, Yano M, Ando T, et al. 2013. Gain-of-function mutations in RIT1 cause Noonan syndrome, a RAS/MAPK pathway syndrome. Am J Hum Genet 93: 173-810. doi:10.1016/j.ajhg.2013.05.021

Berger AH, Imielinski M, Duke F, Wala J, Kaplan N, Shi GX, Andres DA, Meyerson M. 2014. Oncogenic RIT1 mutations in lung adenocarcinoma. Oncogene 33: 4418-4423. doi:10.1038/onc.2013.581

Boycott KM, Innes AM. 2017. When one diagnosis is not enough. N Engl J Med 376: 83-85. doi:10.1056/ NEJMe1614384

Döcker D, Schubach M, Menzel M, Spaich C, Gabriel HD, Zenker M, Bartholdi D, Biskup S. 2015. Germline PTPN11 and somatic PIK3CA variant in a boy with megalencephaly-capillary malformation syndrome (MCAP)-pure coincidence? Eur J Hum Genet 23: 409-412. doi:10.1038/ejhg.2014.118

Gripp KW, Schill L, Schoyer L, Stronach B, Bennett AM, Blaser S, Brown A, Burdine R, Burkitt-Wright E, Castel P, et al. 2020. The sixth international RASopathies symposium: precision medicine-from promise to practice. Am J Med Genet A 182: 597-606. doi:10.1002/ajmg.a.61434

Houge G. 2015. Where is the boundary between diagnostics and research? Tidsskr Nor Laegeforen 135: 1632. doi:10.4045/tidsskr.15.0817

Hynds DL, Spencer ML, Andres DA, Snow DM. 2003. Rit promotes MEK-independent neurite branching in human neuroblastoma cells. J Cell Sci 116: 1925-1935. doi:10.1242/jcs.00401

Keppler-Noreuil KM, Rios JJ, Parker VE, Semple RK, Lindhurst MJ, Sapp JC, Alomari A, Ezaki M, Dobyns W, Biesecker LG. 2015. PIK3CA-related overgrowth spectrum (PROS): diagnostic and testing eligibility criteria, differential diagnosis, and evaluation. Am J Med Genet A 167A: 287-295. doi:10.1002/ajmg.a .36836 
Kouz K, Lissewski C, Spranger S, Mitter D, Riess A, Lopez-Gonzalez V, Lüttgen S, Aydin H, von Deimling F,

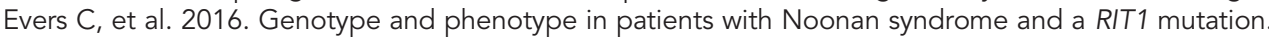
Genet Med 18: 1226-1234. doi:10.1038/gim.2016.32

Mirzaa G, Conway R, Graham JM Jr, Dobyns WB. 2013. PIK3CA-related segmental overgrowth. In GeneReviews ${ }^{\circledR}$ [Internet] (ed. Adam MP, Ardinger HH, Pagon RA, et al.), pp. 1993-2021. University of Washington, Seattle, WA.

Mirzaa G, Timms AE, Conti V, Boyle EA, Girisha KM, Martin B, Kircher M, Olds C, Juusola J, Collins S, et al. 2016. PIK3CA-associated developmental disorders exhibit distinct classes of mutations with variable expression and tissue distribution. $\mathrm{JCl}$ insight 1: e87623. doi:10.1172/jci.insight.87623

Posey JE, Harel T, Liu P, Rosenfeld JA, James RA, Cogan Akdemir ZH, Walkiewicz M, Bi W, Xiao R, Ding Y, et al. 2017. Resolution of disease phenotypes resulting from multilocus genomic variation. $N$ Engl $J$ Med 376: 21-31. doi:10.1056/NEJMoa1516767

Richards S, Aziz N, Bale S, Bick D, Das S, Gastier-Foster J, Grody WW, Hegde M, Lyon E, Spector E, et al. 2015. Standards and guidelines for the interpretation of sequence variants: a joint consensus recommendation of the American College of Medical Genetics and Genomics and the Association for Molecular Pathology. Genet Med 17: 405-424. doi:10.1038/gim.2015.30

Robertson SP, Gattas M, Rogers M, Adès LC. 2000. Macrocephaly-cutis marmorata telangiectatica congenita: report of five patients and a review of the literature. Clin Dysmorphol 9: 1-9. doi:10.1097/00019605200009010-00001

Shi GX, Jin L, Andres DA. 2011. A rit GTPase-p38 mitogen-activated protein kinase survival pathway confers resistance to cellular stress. Mol Cell Biol 31: 1938-1948. doi:10.1128/MCB.01380-10

Vichas A, Riley AK, Nkinsi NT, Kamlapurkar S, Parrish PCR, Lo A, Duke F, Chen J, Fung I, Watson J, et al. 2021. Integrative oncogene-dependency mapping identifies RIT1 vulnerabilities and synergies in lung cancer. Nat Commun 12: 4789-4807. doi:10.1038/s41467-021-24841-y 


\section{COLD SPRING HARBOR Molecular Case Studies}

\section{The blended phenotype of a germline RIT1 and a mosaic PIK3CA variant}

Siren Berland, Jørgen Jareld, Nicholas Hickson, et al.

Cold Spring Harb Mol Case Stud 2021, 7: a006121

Access the most recent version at doi: $10.1101 / \mathrm{mcs} . a 006121$

References

License

Email Alerting Service
This article cites 15 articles, 2 of which can be accessed free at: http://molecularcasestudies.cshlp.org/content/7/6/a006121.full.html\#ref-list-1

This article is distributed under the terms of the Creative Commons Attribution-NonCommercial License, which permits reuse and redistribution, except for commercial purposes, provided that the original author and source are credited.

Receive free email alerts when new articles cite this article - sign up in the box at the top right corner of the article or click here. 